\title{
Laparoscopic Cholecystectomy In Acute Calculus Cholecystitis-Experience At District Level Hospital
}

\author{
SK Biswas ${ }^{1}, \mathrm{JC}_{\mathrm{Saha}}^{2}$, MM Rahman ${ }^{3}$, MA Rahman ${ }^{4}$
}

\begin{abstract}
Laparoscopic cholecystectomy has become the gold standard treatment for symptomatic gallbladder disease. Its role in surgical treatment of acute cholecystitis has also been well defined. Here a prospective study was conducted over a 3 year period of 28 patients with acute cholecystitis at district level hospitals of Bangladesh, where many modern surgical facilities were lacking. Out of 28 patients of acute cholecystitis, 24 were operated by laparoscopic methods and rests 4 were converted to open cholecystectomy. Mean operation time was 87.95 minutes and only 2 patients had postoperative complications. This study showed the appropriate time of laparoscopic cholecystectomy for acute cholecystitis, conversion rate and complications. It may be concluded that laparoscopic cholecystectomy is feasible and beneficial to the patient with acute cholecystitis in its early phase, if necessary support and expertise is available.
\end{abstract}

Key Wards: Acute cholecystitis, Laparoscopic cholecystectomy, Conversion

\section{Introduction}

Laparoscopic Cholecystectomy has been established as the gold standard for symptomatic gallstone diseases. Advantages includes a shortened hospital stay, decreased recovery time, reduction in postoperative pain, earlier return to full activity and an improved cosmetic results ${ }^{1,2}$. Acute cholecystitis once considered a contraindication to laparoscopic cholecystectomy ${ }^{3,4}$. However, because of increasing experience and confidence in laparoscopic cholecystectomy, the indications were extended to include patients with acute cholecystitis. Several randomized and nonrandomized studies have documented the feasibility and safety of laparoscopic cholecystectomy for acute cholecystitis in experienced hands ${ }^{5-9}$. This prospective study was designed to analyze the results of laparoscopic cholecystectomy in patients with features suggestive of acute cholecystitis.

1. Dr. Swapan Kumar Biswas, FCPS (Surgery), MRCS (Edin), Junior Consultant, Dept. of Surgery, FMCH, Faridpur.

2. Dr. Jitesh Chandra Saha, FCPS (Surgery), FRCS (Edin), Assistant Professor, Dept. of surgery, FMC, Faridpur.

3. Dr. Md. Mahfuzur Rahman, MBBS, Assistant Registrar, Dept. of surgery, FMCH, Faridpur.

4. Dr. Md. Ataur Rahman, MS (General Surgery), Professor and Head of Dept. of surgery, FMC, Faridpur.

Address of correspondence

Dr. Swapan Kumar Biswas, FCPS (Surgery), MRCS (Edin), Junior Consultant, Department of surgery, Faridpur Medical College Hospital.

Telephone: +88-01712120828, E-mail: swapan_kb@yahoo.com

\section{Materials and Methods}

This study included 28 patients who underwent laparoscopic cholecystectomy for acute cholecystitis at Faridpur Central Hospital and Faridpur Medical College Hospital, Bangladesh, between July 2006 and June 2009. All patients had preoperative, operative and postoperative data recorded. Additional data recorded included conversion to open cholecystectomy and the reason for conversion, operative duration, length of postoperative stay, and any postoperative complications. These data were stored and analyzed using a personal computer and data processing software.

All patients were admitted on an emergency basis. The diagnosis of acute cholecystitis was based on the presence of at least 2 of the following criteria: (1) acute upper abdominal pain and Murphy's sign, (2) fever $>36.5^{\circ} \mathrm{C}$ and white blood cell count $>10 \times 10^{9} / \mathrm{L}$, and (3) Ultrasound findings of thick walled gallbladder, distended gallbladder, ultrasounds Murphy's sign, and pericholecystic fluid, in the presence of gallstones. Exclusion criteria included (1) patient who had no gallstones, (2) those who were not operated on, (3) those who had delay due to obstructive jaundice, ascending cholangitis, biliary pancreatitis, or co morbid diseases.

Because previous reports have shown that laparoscopic cholecystectomy for acute cholecystitis is best performed with in 72 hours after onset of pain ${ }^{7,9-11}$, the 
patients were divided into two groups, depending on the timing of laparoscopic cholecystectomy after onset of pain: group 1 with in 72 hours and group 2 after 72 hours. On admission, all patients received intravenous second generation cephalosporin plus Metronidazole, which were continued for 24 hours after surgery. Laparoscopic cholecystectomy was performed by same surgeon. All the patients underwent standard four ports techniques. No Intraoperative cholangiogram was performed.

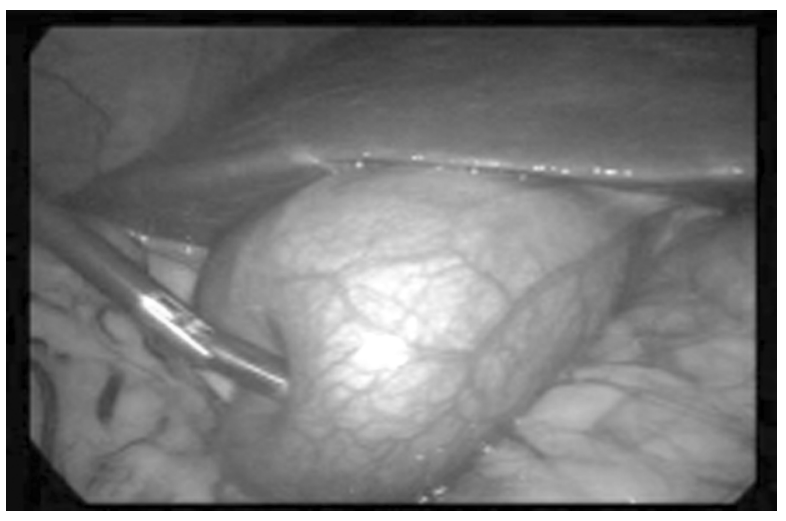

Figure 1: A case of acute cholecystitis 48 hours old. Gall bladder is redden, vessels are engorged and no adhesion.

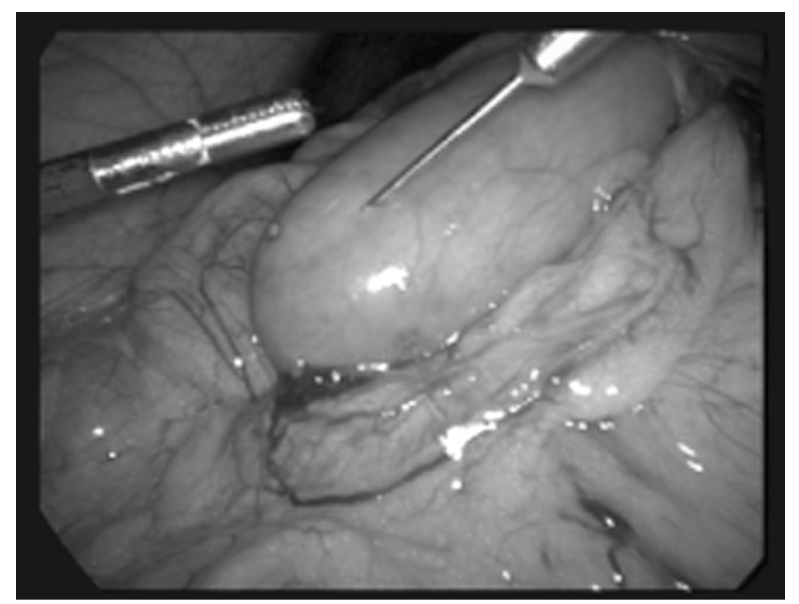

Figure 2: A case of acute cholecystitis 7 days old. Note that gallbladder is whitish in color containing pus and adhesion with omentum.

\section{Results}

Of 28 patients undergoing laparoscopic cholecystectomy for acute calculus cholecystitis $75 \%$ (21) were females and $25 \%(07)$ were male. Mean age was 40.14 years (range, 18 to 70). Laparoscopic cholecystectomy was performed within 72 hours after onset of pain in 13 patients (group 1) and after 72 hours in 15 patients (Table I). Both groups were matched in terms of clinical manifestation and ultra sounds findings (Table II).

Table I: Patients group based on duration of symptoms

\begin{tabular}{lllll}
\hline Group & Duration & Total & Male & Female \\
\hline 1 & $<72$ hours & $13(46.42)$ & $3(23.07)$ & $10(76.93)$ \\
2 & $>72$ hours & $15(53.58)$ & $4(26.66)$ & $11(73.34)$ \\
\hline
\end{tabular}

Table II: Clinical manifestation and ultrasounds finding in patient with acute calculus cholecystitis undergoing laparoscopic cholecystectomy

\begin{tabular}{rrr}
\hline Characteristics & Group 1, LC within & Group 2, LC after \\
72 hours (n=13) & 72 hours $(\mathrm{n}=15)$ \\
\hline
\end{tabular}

$\begin{array}{lrr}\text { - Pain in right hypochondrium, } \mathrm{n}(\%) & 12(92.30) & 9(60) \\ \text { - Murphy's sign, } \mathrm{n}(\%) & 8(61.53) & 6(40) \\ \text { - Fever }>37.5^{0} \mathrm{C}, \mathrm{n}(\%) & 9(69.23) & 7(46.66) \\ \text { - WBC }>10 \mathrm{x} 10^{9} / \mathrm{L}, \mathrm{n}(\%) & 11(84.61) & 10(66.66) \\ \text { - Ultrasounds results } & & \\ \checkmark \text { Gallstones, } \mathrm{n}(\%) & 13(100) & 15(100) \\ \checkmark \text { Distended gallbladder, } \mathrm{n}(\%) & 12(92.30) & 11(73.33) \\ \checkmark \text { Thick walled gallbladder, } \mathrm{n}(\%) & 12(92.30) & 12(80) \\ \checkmark \text { Pericholecystic fluid, } \mathrm{n}(\%) & 05(38.46) & 02(13.33)\end{array}$

Table III: Results of laparoscopic cholecystectomy for acute cholecystitis

\begin{tabular}{lll}
\hline Characteristics & Group 1, LC within & Group 2, LC after \\
& 72 hours $(\mathrm{n}=13)$ & 72 hours $(\mathrm{n}=15)$
\end{tabular}

\begin{tabular}{lrr}
\hline Conversion, $\mathrm{n}(\%)$ & $0(0)$ & $4(26.66)$ \\
Operation time, minutes & 72.69 & 110 \\
Complications, $\mathrm{n}(\%)$ & 0 & $2(13.33)$ \\
Postoperative stay, days & 2 & 3.5
\end{tabular}

Table III shows results of laparoscopic cholecystectomy for acute calculus cholecystitis. Conversion to open cholecystectomy was required in $04(14.28 \%)$ patients all were in group 2. Reason for conversion was unable to identify structures of callots triangle in 2 patients, bleeding in 1 case and difficult to hold and retract gallbladder in 1 case. Average trial dissection before conversion was 25 minutes. The mean operation time, excluding those requiring conversion, was 87.95 minutes (range, 30 to 210). Laparoscopic findings revealed that 10 patients had no adhesion around gallbladder area, 
11 patients had mild to moderate and 7 patients had severe adhesion. 25 patients were found to have impacted stone in the infundibulum. 20 patients had distended gallbladder where aspiration was done to facilitate grasping of the gall bladder wall. All patients had mild to severe form of wall thickening due to oedema. 09 patients had rupture of gall bladder because of fragile wall and were managed by suction, and lavage with normal saline mixed with povidone iodine solution, and gallbladder was taken out by putting it in the retrieval bag (improvised by using surgical gloves). 5 patients had too big stone in distended gall bladder that required enlargement of umbilical port during extraction of gall bladder. In 12 patients sub-hepatic drain was placed, which persisted for 24-48 hours. There were $02(7.14 \%)$ complications all were limited to group 2, one had subphrenic abscess and another had umbilical port site wound infection. The mean postoperative stay was 2.5 days (range, 1 to 5). No mortalities and no bile duct injury occurred in this study.

\section{Discussion}

In prelaparoscopy era, the traditional management of patients with acute cholecystitis was initial conservative treatment to "cool down" the inflamed gallbladder followed by delayed open cholecystectomy 6 to 8 weeks later. This approach however was challenged by early cholecystectomy, first advocate by Essenhigh in $1966^{12}$. Since then, several randomized studies have shown that early open cholecystectomy for acute cholecystitis is as safe as delayed cholecystectomy with reduced morbidity and hospital stay, lower costs, and rapid recovery ${ }^{12,14}$.

It appears that laparoscopic treatment of acute cholecystitis is following the same trend as open cholecystectomy. Initially laparoscopic cholecystectomy was contraindicated in patients with acute cholecystitis because of fear of increased morbidity due to bile duct injury and high conversion rate but greater experience with laparoscopic cholecystectomy has led many centers to attempt laparoscopic cholecystectomy in patients with diagnosis of acute cholecystitis ${ }^{5-9}$. A review of the literature over the past decade shows that early laparoscopic cholecystectomy for acute cholecystitis is extremely safe $4,9,16,17$. This approach is well supported by a recent international consensus published as Tokyo Guidelines ${ }^{18}$.
In our country, laparoscopic management of gall stone diseases is still mainly confined to the cases of chronic cholecystitis but in acute cholecystitis late laparoscopic cholecystectomy (interval laparoscopic cholecystectomy) is done. In one study in BIRDEM, Dhaka center of 32 patients with acute cholecystitis undergoing early laparoscopic cholecystectomy shows good results, mean operation time 54.54 minutes, conversion rate $9 \%$ and only 7 patients had minor postoperative complication with out any major bile leakage or CBD injury ${ }^{15}$.

All the patients in this series were operated with the history of acute attack and on basis of onset of pain, divided into two groups, (1) group 1: laparoscopic cholecystectomy done with in 72 hours after onset of pain and (2) group 2: laparoscopic cholecystectomy done after 72 hours after onset of pain. Mean time required for laparoscopic cholecystectomy in this series was 87.95 minutes which ranged from 30 to 210 minutes. Mean operation time is lengthy in group 2 (110 minutes) than group 1 (72.69 minutes).

The question of relating the timing of laparoscopic cholecystectomy for acute cholecystitis to admission or onset of symptoms has been over emphasized ${ }^{5,7,16,21}$. In our series those who were operated with in 72 hours after onset of symptoms (group 1) had no conversion and no complication but in group 2, 4 patients required conversion and 2 developed postoperative complication. Based on international experience and our results, we support laparoscopic intervention with in 72 hours after onset of symptoms for acute cholecystitis. It is our observation that laparoscopic cholecystectomy with in this period is technically less demanding because the oedema planes magnify the structures and facilitate dissection--an argument similar to historic findings in early open cholecystectomy for acute cholecystitis.

In this series, the overall conversion rate is $14.28 \%$ which falls with in range reported in prior studies (0 to $39 \%)^{6,8,19}$. Most common reason for conversion among our patients was unable to identification of structures of callots triangle safely due to inflammatory changes.

Post operative complications were also negligible. Only 2 patients in group had complications, one had subphrenic abscess treated with percutaneous aspiration under ultrasonogram guidance and one had umbilical port site infection which was resolved with in few days with antibiotics and dressing. No reported bile leakage or major bile duct injury occurred in this series. 


\section{Conclusion}

Laparoscopic cholecystectomy for acute cholecystitis performed with in same admission is safe and associated with a low conversion rate and no mortality. However, laparoscopic cholecystectomy should be performed as early as possible, preferably with in the golden period of 72 hours after onset of symptoms, to decrease the operation time, conversion rate, morbidity rate and total hospital stay.

\section{References}

1. Buanes T, Mjaland O. Complications in laparoscopic and open cholecystectomy: a prospective comparative trial. Surg Laparosc Endosc. 1996;6:266-272.

2. Paulino-Netto A. A review of 391 selected open cholecystectomies for comparison with laparoscopic cholecystectomy. Am J Surg. 1991;166:71-73.

3. Schirmer BD, Edge SB, Dix J, Hyser MJ, Hanks JB, Jones RS. Laparoscopic cholecystectomy. Treatment of choice for symptomatic cholecystitis. Ann Surg. 1991;213:665-676.

4. Cuscheiri A, Berci G, McSherry CK. Laparoscopic cholecystectomy. Am J Surg. 1990;159:273.

5. Garber SM, Korman J, Cosgrove JM, Cohen JR. Early laparoscopic cholecystectomy for acute cholecystitis. Surg Endosc. 1997;11:347-350.

6. Stevens KA, Chi A, Lucas LC, Porter JM, Williams MD. Immediate laparoscopic cholecystectomy for acute cholecystitis: no need to wait. Am J Surg. 2006;192:756-761.

7. Lo CM, Liu CL, Fan ST, Lai ECS, Wong J. Prospective randomized study of early versus delayed laparoscopic cholecystectomy for acute cholecystitis. Ann Surg. 1998;227:461-467.

8. Johanson M, Thune A, Blomqvist A, Nelvin L, Lundell L. Management of acute cholecystitis in laparoscopic era: results of a prospective, randomized clinical trial. J Gastrointest Surg. 2003;7:642-645.

9. Papi C, Catarci M, D'Ambrosio L, Gili L, Koch M, Grassi GB, et al. Timing of cholecystectomy for acute cholecystitis: a metaanalysis. Am J Gastroenterol. 2004;99:147-155.

10. Rattner DW, Ferguson C, Warshaw AL. Factors associated with successful laparoscopic cholecystectomy for acute cholecystitis. Ann Surg. 1993;217:233-7.

11. Yadav RP, Adhikary S, Agrawal CS, Bhattarai B, Gupta RK, Ghimire A. A comparative study of early vs. delayed laparoscopic Cholecystectomy in acute cholecystitis. Kathmandu University Medical Journal 2009;7(1):16-20.

12. Essenhigh DM. Management of acute cholecystitis. Br J Surg. 1966;53:1032-1038.

13. Javinen HJ, Hastbacka J. Early cholecystectomy for acute cholecystitis: a prospective randomized study. Ann Surg. 1980;191:502-505.

14. Norrby S, Herlin P, Holmin T, Sjodahl R, Tagesson C. Early or delayed cholecystectomy in acute cholecystitis? A clinical trial. Br J Surg. 1983;70:163-165.

15. Maitra TK, Alam NA, Haque E, Khan MH, Chowdhury HK. Laparoscopic Cholecystectomy in Acute Gall bladder Disease. J Bangladesh Coll Phys Surg. 2006;24:10-13.
16. Al-Mulhim, Abdulmohsen A. Timing of Early Laparoscopic Cholecystectomy for Acute Cholecystitis. Journal of the Society of Laparoendoscopic Surgeons 2008;12:82-287.

17. Sinha R, Sharma N. Acute Cholecystitis and Laparoscopic Cholecystectomy. Journal of the Society of Laparoendoscopic Surgeons 2002;6:65-68.

18. Yamashita Y, Takada T, Kawarada Y, Nimura Y, Hirota M, Miura F, et al. Surgical treatment of patients with acute cholecystitis: Tokyo Guidelines. J Hepatobiliary Pancreat Surg. 2007;14:91-97.

19. Bhattacharya D, Senapati PSP, Hurle R, Ammori BJ. Urgent versus interval laparoscopic cholecystectomy for acute cholecystitis: a comparative study. J Hepatobiliary Pancreat Surg. 2002;9:538-542.

20. Soffer D, Blackbourne LH, Schulman CI, Goldman M, Habib F, Benjamin R, et al. Is there is an optimal time for laparoscopic cholecystectomy in acute cholecystitis? Surg Endosc. 2007;27:805-809. 